\title{
An Empirical Study on Spatial Presence in Immersive Geo-Environments
}

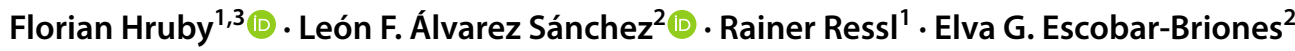

Received: 11 September 2019 / Accepted: 29 February 2020 / Published online: 25 March 2020

(c) The Author(s) 2020

\begin{abstract}
Research on immersive virtual reality (VR) indicates that VR technologies facilitate understanding through the formation of spatial presence, which is the user's feeling of "being there" in a virtual place. These findings make VR a highly interesting tool for geographic information science and the visualization of geospatial phenomena. However, immersion and presence are often studied under laboratory conditions, while research on virtual representations of real-world environments is still rare. This paper aims to reduce this gap empirically through a user study on spatial presence in immersive geo-environments. A total of 60 subjects entered a VR replica of a coral reef in the Mexican Caribbean built upon WorldView2 imagery. After testing within- and between-subject performance under both VR headset- and desktop-based visualization conditions, all users completed the IPQ self-report questionnaire to evaluate the sense of presence experienced. The results indicate a strong effect of immersion, leading to statistically significant higher levels of spatial presence in immersive geo-environments.
\end{abstract}

Keywords Virtual reality $\cdot$ Spatial presence $\cdot$ Immersion $\cdot$ Geovisualization $\cdot$ Immersive geo-environments

\section{Zusammenfassung}

Räumliches Präsenzerleben in immersiven geographischen Umgebungen - eine empirische Studie. Aktuelle Forschungen weisen darauf hin, dass mittels immersiver virtueller Realität (VR) ein intensives räumliches Präsenzerleben (Telepräsenz) erzeugt werden kann, bei dem sich NutzerInnen im virtuellen Raum anwesend bzw. handlungsfähig fühlen. Empirische Studien legen außerdem nahe, dass mit dem Gefühl der Telepräsenz ein gesteigertes Interesse am dargestellten Sachverhalt bzw. ein besseres Verständnis desselben einhergehen. Da es den Geoinformationswissenschaften immer auch um die möglichst gute Vermittlung raumbezogenen Wissens geht, kommt dem Phänomen des räumlichen Präsenzerlebens besondere Bedeutung für die Geovisualisierung zu. Allerdings stützen sich empirische Befunde zur Wirkung von VR meist auf fiktive Umgebungen, während georeferenzierte geographische Räume bislang weitgehend unerforscht sind. Der vorliegende Text möchte diese Forschungslücke anhand einer Nutzungsstudie zur Telepräsenz in einer realistischen immersiven Umgebung verkleinern. 60 ProbandInnen testeten eine satellitenbild- und eine GIS-basierte virtuelle Repräsentation eines Korallenriffs. Sowohl inter- als auch intraindividuelle Leistungen wurden unter immersiven (VR-Brille) und desktop-basierten Untersuchungsbedingungen verglichen. Die Ergebnisse sprechen für einen starken Einfluss von Immersion auf die NutzerInnen, welcher in einem statistisch betrachtet signifikant höherem Präsenzerlebnis in immersiven Geovisualisierungen zum Ausdruck kommt.

Florian Hruby

florian.hruby@univie.ac.at

1 National Commission for Knowledge and Use of Biodiversity (CONABIO), 14010 Mexico City, Mexico

2 Institute of Ocean Sciences and Limnology, National Autonomous University of Mexico (UNAM), Mexico City, Mexico

3 Department of Geography and Regional Research Cartography and Geoinformation, University of Vienna, Universitätsstr. 7, 1010 Vienna, Austria 
Schlüsselwörter Virtuelle Realität · Telepräsenz · Immersion · Geovisualisierung · Immersive Umgebung

\section{Introduction}

Immersive virtual environments (IVE), made accessible via stereoscopic head-mounted displays (HMD), have become a frequently emphasised topic in the geovisualization research agenda. IVE are already applied at local (Edler et al. 2019), regional (Lütjens et al. 2019) and global (Yang et al. 2018) scales, visualizing past (Tschirschwitz et al. 2019), present (Hruby et al. 2019) and potentially even future scenarios of real geographic space and place (Edler et al. 2018).

The virtual reality (VR) capabilities of current geographic information systems (GIS) are as yet limited; however, computer game engines provide a commonly used middleware platform between GIS and HMD (Edler et al. 2018; Hruby et al. 2019), although they make building IVE from geodata a time- and labour-consuming process.

Geographic information scientists usually justify the time and effort put into the development of IVE by arguing that high-immersive VR technology (compared to low-immersive desktop-based VR) facilitates communication of spatial phenomena. However, a closer look at this conclusion reveals several shortcomings, and brings into question the general utility of IVE for geovisualization matters.

Firstly, the hypothesis of a particular explanatory power of IVE is taken from cognitive research on spatial presence. In doing so, it must be borne in mind that the concept of presence itself is only partly understood, and different viewpoints on the formation of spatial presence have been argued in the scientific literature (Cummings and Bailenson 2016; Skarbez et al. 2018). Secondly, user-studies on spatial presence mainly rely on fictitious settings, while immersive replicas of real-world environments have remained untested to date.

In this context, the present paper aims to reduce the gap in research on IVE through an empirical study of spatial presence in an immersive geo-environment of a Caribbean coral reef: we will begin with a critical definition of both presence and immersion, then analyse and typologize immersive geovisualization products in the light of these key concepts. As we will see, at least two different approaches can be taken to the representation of geodata in virtual space, and different conclusions regarding the formation of spatial presence can be drawn accordingly. Once a sound terminological setting is established, we will present our main hypothesis, together with the methodology applied and the results obtained in the question: can high-immersive geo-environments facilitate a stronger experience of spatial presence than low-immersive types of cartographic visualization?

\section{Spatial Presence in Immersive Environments}

The concepts of both spatial presence and immersion are a constant source of confusion in academic discussion. We therefore provide a short description of why and how we will use each of these terms within this study. Readers with a deeper interest in the origin and application of both concepts are referred to Skarbez et al. (2018) for further reading.

\subsection{Presence vs. Immersion}

In the realm of VR environment research, presence is generally understood as a shortened version of telepresence, which we can define as "psychological state in which virtual [...] objects are experienced as actual objects" (Lee 2004). Spatial and social presence are considered the main types of telepresence (IJsselsteijn et al. 2000; Lombard and Jones 2015), referring respectively to the feeling of being there and being together with others in a mediated environment (Skarbez et al. 2018; Oh et al. 2018). Here, we focus on the spatial dimension of telepresence, i.e. the user's experience of being situated in VR space and directly interacting with the virtual environment (Hartmann et al. 2015b).

These two aspects, i.e. self-location and action possibilities, were formalized through a two-step model of the formation of spatial presence by (Wirth et al. 2007) (later enhanced by Schubert 2009 and Wirth et al. 2012), in which a mental spatial model of the IVE must be developed (step 1) and accepted by the user as their "primary egocentric reference frame" (Wirth et al. 2007) (step 2), so that the spatial presence can emerge. In accordance with this model, the formation of spatial presence therefore depends on both user-(e.g., interest, spatial ability) and application-specific features (e.g., spatial cues, consistency). Measures to access spatial presence are summarized by Hartmann et al. (2015a)

In contrast to spatial presence, which we define as the user's experience of "being there", immersion refers to technological qualities of VR media. In line with recent literature (Cummings and Bailenson 2016), we consider the use of stereoscopic head-mounted displays (HMD) as an identifying characteristics of high-immersive environments, since this equipment facilitates an "[...] inclusive, extensive, surrounding and vivid illusion of reality" (Slater and Wilbur 1997).

Like presence, immersion is also a multidimensional concept, with tracking level, stereoscopic vision, image 
quality, field of view and update rate being some of the major immersive features considered by current research.

\subsection{Spatial Presence through Immersion?}

Academia's interest in spatial presence is based upon the assumption that an increased sense of presence facilitates understanding and involvement with the phenomena visualized, thus positively affecting the mental maps users generate from geovisualization products. This assumption draws upon a growing body of empirical research on the effectiveness of spatial presence in VR environments for a variety of cartographically relevant purposes, e.g. learning (Bachen et al. 2016; Cho 2018), training (Cummings and Bailenson 2016), credibility (Kang et al. 2019) and entertainment (Tamborini and Bowman 2010).

However, an in-depth understanding has yet to be reached in terms of how the relative importance of the user- and application-specific features of IVE can influence the formation of spatial presence. Hence, we have an as yet limited knowledge regarding the effect of immersion on the user's spatial mind. In a meta-analysis of 83 studies on both high- and low-immersive VR environments, (Cummings and Bailenson 2016) found only a medium-sized effect of immersive VR technology on presence while, on the other hand, analogue media such as books or movies can also provide users with an experience of spatial presence (Schubert and Crusius 2002).

Consequently, (also among geographic information scientists) the common acceptance that IVE will automatically lead to a stronger feeling of spatial formation must be approached with some caution and makes the present user study both timely and necessary.

\section{Immersive Geo-Environments}

In the previous section, we analysed IVE in rather general terms from two perspectives: we introduced spatial presence as a concept that allows us to model and measure the effects of IVE on the user's mind, and used immersion to summarize the important technological characteristics of VR systems. We now apply this dichotomy of IVE in general to the particular characteristics of immersive geo-environments.
First, we propose a rough typology of the approaches taken to date in immersive geovisualization, to contrast these with our understanding of spatial presence.

\subsection{Immersion in Geovisualization}

Two main types of immersive geovisualization products can be distilled from the current literature: On the one hand, IVE have been provided at a 1:1 scale level, allowing the users to experience replicas of real-world places at a level of detail comparable to that which they would have by being physically there (Edler et al. 2019; Tschirschwitz et al. 2019), i.e. from an egocentric first-person perspective.

On the other hand, geographic information scientists also explore different types of 1: $x$ (with $x>1$ ) scaled data representations (e.g. by combing world-maps and globes (Yang et al. 2018), or maps and diagrams in virtual space (Havenith et al. 2019), where map-space and map user are separated so that users must bring themselves into a relationship with the information displayed in terms of a third-person perspective (Fig. 1). This means that VR has been adopted as a new medium for both abstract (third-person) and realistic (first-person) visualization of spatial data.

Regardless of scale, and due to the limited VR capabilities of current GIS, both first- and third-person applications commonly use game engines (e.g. Unreal Engine ${ }^{\circledR}$ or Unity $3 \mathrm{D}()$ as middleware with which to make geodata VR- and HMD-ready.

A particular challenge of photo-realistic geovisualization in VR is the collection of geometries and textures at a high resolution. While modern laser scanning methods allow the mapping of even fine levels of object detail, especially for built (e.g. urban) and closed spaces (e.g. caves) (Kersten et al. 2018; Zambrano et al. 2017), semi-automatic or even manual modelling is required to include environments that are difficult to access (e.g. tropical or underwater ecosystems) or dynamic agents that are difficult to capture (e.g. flocks of birds).

Several feasible workflows for immersive first-person cartographies have been presented to date (Edler et al. 2018; Hruby et al. 2019; Kersten et al. 2018).
Fig. 1 Examples of third-person immersive geo-environments from (Yang et al. 2018) kindly provided by the authors)

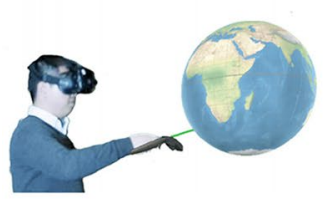

(a) Exocentric globe

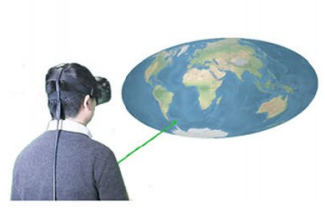

(b) Flat map

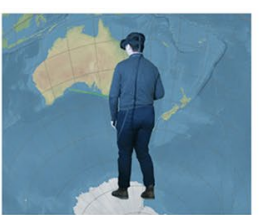

(c) Egocentric globe

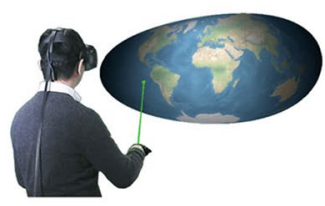

(d) Curved map 


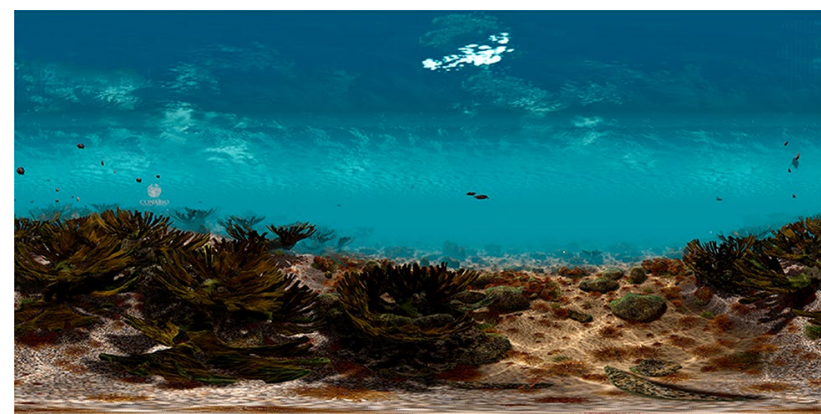

Fig. $2360^{\circ}$ render of an immersive geo-environment in the Mexican Caribbean

\subsection{Spatial Presence in Geovisualization}

To our knowledge, neither of the two aforementioned approaches to immersive geovisualization has been tested empirically for its effects on presence. However, to take a first step towards a deeper understanding of spatial presence in immersive geovisualization environments, we consider first-person IVE a better research candidate than approaches based on 1: $x$ for the following reason: in common paperor desktop-based maps, users perceive a clear difference between map-space and their own position in physical space, and this dichotomy remains when users perceive 1: $x$ scaled maps in virtual space using immersive technology (i.e. a HMD, cf. Fig. 1), since there remains a perceptible difference between the virtual map-space and their own position in virtual space.

In first-person IVE, this difference no longer holds true. Rather, users become part of the immersive environment, and perceive the virtually represented place as they would by being physically there at a 1:1 scale (Fig. 2).

In accordance with the definition of spatial presence as the feeling of being there in a mediated environment, first-person cartographies therefore provide a more genuine experimental platform with which to evaluate the impact of immersive geovisualization on the user's experience of presence: if we compare a digital globe on a desktop screen with a virtual globe perceived through a HMD, we still have two scenarios in which the user-space and map-space are separated. In contrast, first-person IVE also allow us to develop a better understanding of the still relatively new geovisualization products, where users are immersed in VR and become part of the map.

We do not wish to suggest that spatial presence has no importance for 1: $x$ scaled IVE; this paper simply intends to take a first step towards a better understanding of the potential of spatial presence for geovisualization matters. We aim to make this first move where it seems to be most appropriate, namely for the empirical testing of first-person IVE of real-world geodata.

\section{Experimental Design}

The aim of the presented study is to analyse the influence of immersion on the formation of spatial presence in VR geovisualization products. The general hypothesis is that a higher level of immersion will have a positive effect on the user's feeling of being present in a virtual geo-environment.

Immersion is the principal independent variable used to test this hypothesis. We implemented this variable both in a low- and high-immersive setting through a desktop- and HMD-based VR application respectively. Moreover, the possible effects of gaming experience and experience with the ecosystem being visualized were also considered.

Self-report measures (Hartmann et al. 2015a) are applied to determine the level of spatial presence produced through each of the two immersive settings. Consequently, spatial presence is our dependent variable.

\subsection{Sample}

60 students from the National Autonomous University of Mexico (UNAM) undergraduate population took part in the present study. Of the participants, $61.7 \%$ were female, and the average age was 24.6 years $(\mathrm{SD}=6.5)$. A total of 31 participants were only tested on the high-immersive geoenvironment, while 29 subjects began the experiment using a low-immersive desktop VR application.

\subsection{Apparatus}

We installed the high-immersive geo-environment on an Intel i7-8700 (3.2 GHz) powered PC (32 GB RAM) with a single NVidia ${ }^{\circledR}$ GeForce GTX 1080 Ti GPU (11 GB graphics memory). Test participants accessed the application through an Oculus Rift ${ }^{\circ}$ HMD with a resolution of $2160 \times 1200$ px (1080x1200 px per eye) and an Xbox 360 controller.

The low-immersive desktop VR environment ran on an Alienware ${ }^{\circledR}$ gaming laptop with an Intel i7-7820 (2.9 GHz) CPU (16 GB RAM) and a single NVidia ${ }^{\circledR}$ GeForce GTX 1070 GPU (8 GB graphics memory). Again, participants used an Xbox 360 controller to navigate through the application shown on a 17 inch screen of resolution 1920x1080 px.

Considering the higher computational effort of stereoscopic vs. non-stereoscopic rendering, a slightly stronger hardware setting was chosen for the high-immersive VR application. Subject to the constantly varying visual complexity of the VR scenario (depending on the user's position and viewpoint), a minimum frame rate of $40 \mathrm{fps}$ was provided for both installations. 

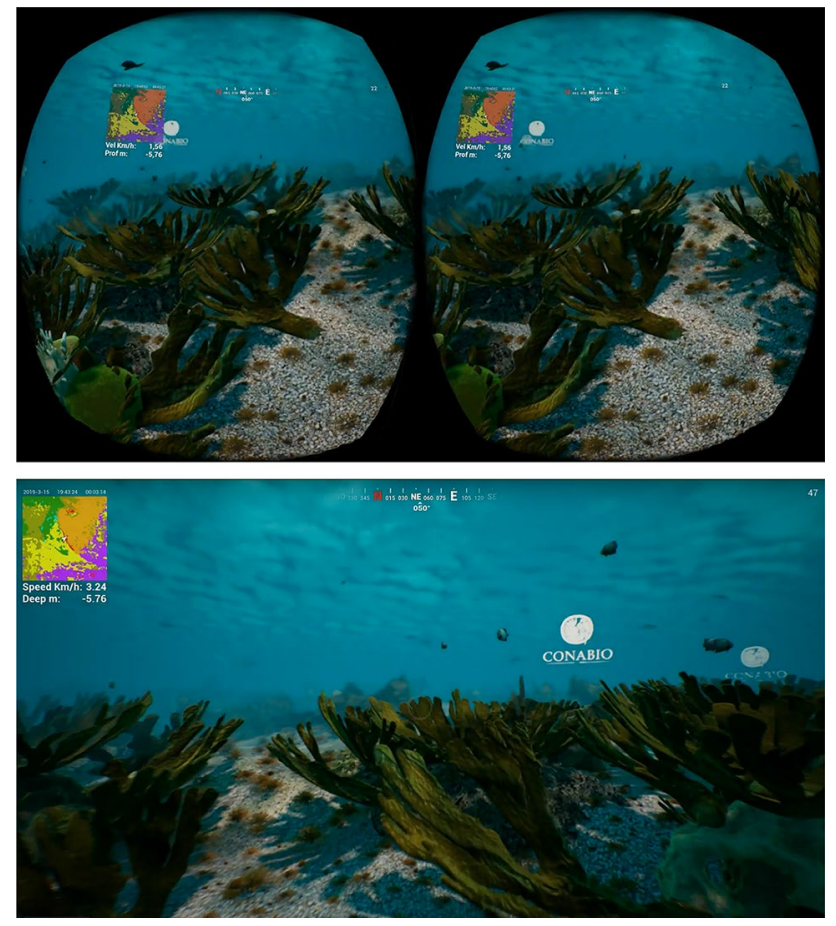

Fig. 3 Test environment under high- (above: Oculus-based) and low(below: desktop-based) immersive conditions

\subsection{Virtual Environment}

A VR replica of a coral reef in the Mexican Caribbean was used for both test environments. The application was built in Unreal Engine ${ }^{\circledR}$ on the basis of bathymetry and benthic habitat maps derived from WorldView-2 imagery (CerdeiraEstrada et al. 2012). This information, together with in situ data was translated into a virtual geo-environment with 28 species (one sea turtle, four fish, six algae, two octocorals, four seagrasses and 11 corals), thus representing a real-world place at a high level of detail (Fig. 3). Technical details on the workflow behind this application have been published by Hruby et al. (2019).

\subsection{Presence Measurement}

To evaluate the level of spatial presence experienced by subjects in our test environment, we relied on the Igroup Presence Questionnaire (IPQ) (Schubert et al. 2001). The IPQ is a self-report measure designed to quantify the sense of presence in VR along three subscales (involvement, realness and spatial presence), together with a general indicator of the user's feeling of "being there". Internal consistency and validity of the IPQ were demonstrated by Schubert (2003) and Regenbrecht and Schubert (2002).

Initially developed in 2001 (Schubert et al. 2001), the IPQ has been applied in numerous studies and translated

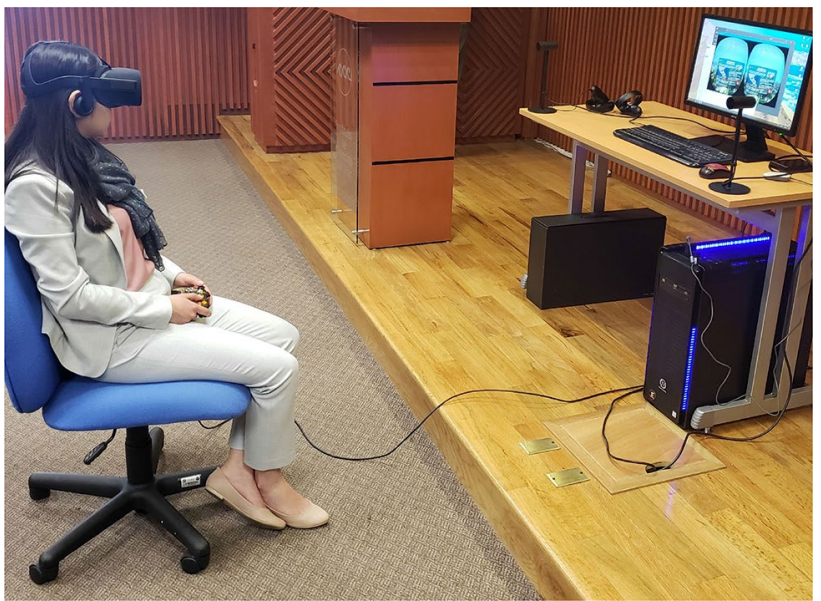

Fig. 4 Experimental design for the high-immersive geo-environment

into various languages over the last two decades (Vasconcelos-Raposo et al. 2016; Iachini et al. 2018). A translation of the IPQ into Spanish was made for the purposes of the present experiment. Questions on gaming and reef-based diving experience were also included at the end of the questionnaire.

\subsection{Procedure}

To avoid ambient noise affecting our results, the study took place in a lecture room of the UNAM's Institute of Ocean Sciences and Limnology, which we equipped for the purpose of the experiment (Fig. 4).

We first introduced subjects to the environment, providing background information on the study site and methods of data acquisition to make it clear that they would enter a realistic representation of an existing place. Participants were further informed that their task would be to activate at least 10 information dashboards in the VR environment to receive additional data on reef fauna and flora. These dashboards were implemented on species-relevant sites and indicated through 3D icons (Fig. 3), where text and audio information could be activated with the Xbox control.

For both immersive and desktop VR environments, we gave operating instructions at a test-site within the application, where the participants remained until feeling familiar with navigation in the VR space and interaction with the task-relevant icons. The application was then reset to a predefined initial point, from which all subjects began their survey of the geo-environment.

Each participant answered the IPQ immediately after completing the test task, but with the application out of reach and sight. 


\section{Results}

IPQ presence ratings were operationalized at the interval measurement level on a seven-point Likert Scale (Edler et al. 2018), transforming the responses into positive numerical values of between 1 (absence of spatial presence) and 7 (highest level of spatial presence). R (version 3.5.3) was used for the statistical analysis.

\subsection{Experiment A: Between-Subject Analysis}

In a first step of the statistical data analysis, we compared the between-subjects effects of the two VR conditions (Oculus Rift vs. desktop) on IPQ scores. Since the assumption of normality held true for the total IPQ ratings, we calculated a one-tailed, non-paired Student's $t$ test to determine differences between the groups.

On average, users of the Oculus Rift reported higher presence ratings $(M=72.48, \mathrm{SD}=7.66)$ than subjects tested on the desktop VR environment $(M=65.48, \mathrm{SD}=15.01)$. This difference was statistically significant at the 0.05 level $(t=$ $2.25, \mathrm{df}=40.96$ ).

A one-way ANOVA was performed to examine differences in IPQ scores depending on gender, and on gaming and diving experience. While there was a main effect of diving experience with $F(1,58)=3.28, p<0.05$, gender, age and gaming experience did not show a statistically significant impact on the subjects' experience of spatial presence (Table 1).

\subsection{Experiment B: Within-Subject Analysis}

To supplement the findings of experiment A using withinsubject data, we asked the participants who had begun the experiment with the desktop VR version to then repeat the test procedure (Sect. 4.5) with the Oculus Rift. A total of 26 subjects participated in the second part of the study. To compare results between experiments $\mathrm{A}$ and $\mathrm{B}$, a one-tailed, paired Student's t-test was calculated, since the total IPQ scores again showed a normal distribution.

All but one subject assigned higher IPQ ratings to the Oculus Rift based environment $(M=81.50, \mathrm{SD}=9.61)$ than to the desktop application $(M=66.12, \mathrm{SD}=15.42)$. In

Table 1 Average IPQ scores obtained from experiment A (with statistically significant $(p<0.05)$ differences labelled in bold text)

\begin{tabular}{lllll}
\hline & Oculus & Female & Gamer & Diver \\
\hline Yes & $\mathbf{7 2 . 5}$ & 71.5 & 72.0 & $\mathbf{7 0 . 0}$ \\
No & $\mathbf{6 5 . 5}$ & 67.0 & 70.0 & $\mathbf{7 3 . 5}$ \\
\hline
\end{tabular}

Table 2 Average IPQ scores obtained from experiment B (with statistically significant $(p<0.05)$ differences labelled in bold text)

\begin{tabular}{lllll}
\hline & Oculus & Female & Gamer & Diver \\
\hline Yes & $\mathbf{8 1 . 5}$ & 73.9 & 74.5 & 72.9 \\
No & $\mathbf{6 6 . 1}$ & 71.5 & 70.7 & 73.4 \\
\hline
\end{tabular}

statistical terms, this difference was significant at the 0.05 level $(t=5.691, \mathrm{df}=25)$.

In experiment $\mathrm{B}$, the IPQ scores did not differ significantly for gender, or for gaming or diving experience (Table 2).

\section{Discussion}

\subsection{The Present Study}

Overall, our findings support the hypothesis that highly immersive geo-environments facilitate a stronger experience of spatial presence than low-immersive visualization. Both between- and within-subject measurements indicate significantly higher ratings of presence in the immersive VR applications (cf. Fig. 5).

While these results show promise for the use of immersive technologies in geographic information science, several additional observations can be made.

Regarding the numbers provided in Tables 1 and 2, we can observe in both trails that participants with reef-based diving experience gave lower IPQ scores than those without previous site-relevant knowledge, a difference that proved significant in experiment $\mathrm{A}$. One could argue that immersive geo-environments make a greater impact on those users, who have never seen the real-world referent. However, this
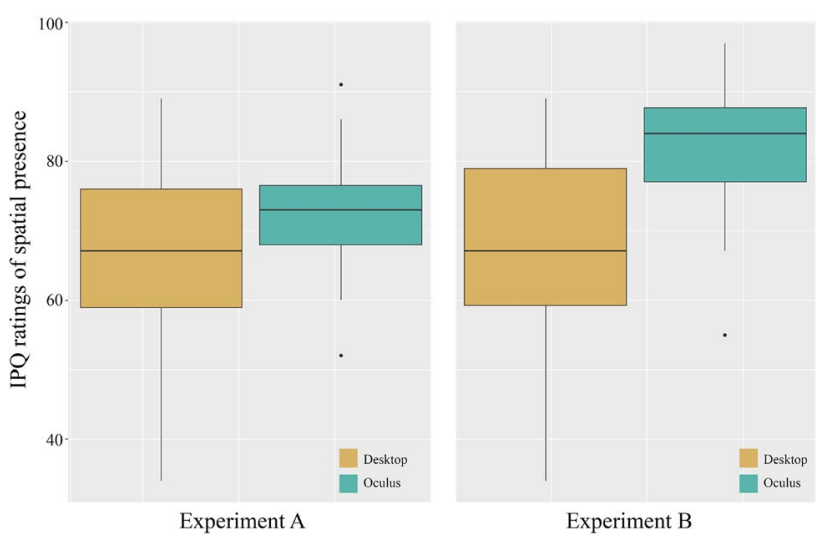

Fig. 5 IPQ scores under high- (Oculus-based) and low- (desktopbased) immersive conditions. Left: within-subject data (experiment A); right: between-subject data (experiment B) 
objection alone would not explain, why the graphically identical desktop version received slightly higher ratings than the Oculus application (cf. Fig. 5). Moreover, we asked participants about diving experience in general, but not about sitespecific knowledge of a Caribbean coral reef. One subject, for instance, reported during debriefing being familiar with the Great Barrier Reef, which is a quite different habitat compared with the ecosystem we tried to simulate. In this regard, it is also worth mentioning that IPQ scores of the high-immersive application differed significantly between experiments $\mathrm{A}$ and $\mathrm{B}$, so that subjects rated the Oculusbased version higher after experiencing the coral reef under desktop conditions. Further research should be dedicated to exploring the impact of previous virtual- and real-world experience on impressions of the virtually represented site.

Another question arising from our results is the possible influence of gaming experience on spatial presence. In both experiments $\mathrm{A}$ and $\mathrm{B}$, computer gamers gave higher IPQ ratings to the geo-environment on the Oculus Rift. Although the observed difference is not backed up by statistical significance, we consider the underlying question relevant for the following reasons: current research on immersive VR frequently focuses on the possible impact of spatial presence on computer game experience (Tamborini and Bowman 2010; Seibert and Shafer 2018), while the effect of gaming experience on presence is hardly considered. Furthermore, a recent experiment on immersive geo-environments reports patterns similar to those we found in the present study, but reports differences of statistical significance (Ahn et al. 2019).

\subsection{Future Research}

Since VR technologies have only recently gone mainstream, the agenda of future research on spatial presence delivered through immersive geovisualization products is large and still growing. In general, we can draw a distinction between basic research on presence and studies applying this concept to immersive geo-environments in particular.

Basic research works on the formalization and modelling (Hartmann et al. 2015b; Wirth et al. 2007), thus aiming for a better understanding on how presence emerges, but also on those features of immersive systems that influence the formation of presence. The existence of a real-world referent is not necessarily a decisive factor for these questions.

For geographic information scientists, on the other hand, analysis and visualization of real or possible (e.g. in terms of scenarios) existing geo-phenomena is fundamental. Hence, examination of the traditional key concepts of cartography provides a possible starting point for approaching spatial presence in immersive geo-environments in a systematic manner.

Among these key concepts, scale is probably the most evident parameter of common maps that is affected by immersive visualization. According to the definition provided in Sect. 2, spatially present users experience the virtual representation of a real place as they would do being physically there. We can label this relationship between VR and physical reality as a spatio-temporal 1:1 scale, allowing the user to unambiguously (i.e.: 1:1) assign virtually experienced models to their real-world referents.

Future research on immersive geo-environments could examine the impact of different levels of detail on presence, in both spatial (e.g. realism of object geometries and textures) and temporal (e.g. simulation of motion patterns of fauna and flora) terms. While we confined the present study to graphical input, geo-environments also provide promising platforms for multimedia cartography applications. This involves not just the effect of different sound settings on spatial presence, but also the implementation of additional human senses (e.g. touch and smell), which are worthwhile and increasingly feasible topics of research in future years. In this regard, navigational aspects and metaphors in terms of a human-computer-interaction will be another defining aspect for a better understanding on how spatial presence in geo-environments could emerge (Sherman and Craig 2018).

Finally, the hyperrealism of immersive geo-environments makes them ideally suited for all kinds of experiments on possible interchangeabilities between real and virtual space. To date, spatial presence has been linked to human agents interacting in VR space. However, we could also consider another kind of spatial presence that allows artificially intelligent agents to perceive real objects as virtual ones.

For instance, consider an unmanned underwater vehicle (UUV) designed to catch invasive fish species. To train this robot in accurate target identification, but also in optimized underwater path-finding, an immersive geo-environment could provide a much more effective learning ambience than any real-world referent. While testing such an UUV in a real coral reef would depend on many external factors (e.g. weather), we can use VR to easily simulate not only every conceivable environmental condition (e.g. lighting conditions, turbidity), but also different parameters of the target species (size, perspective, motion patterns). We are currently testing this possibility with the coral reef VR application shown in Fig. 3. A second example of substituting real by virtual space is the behavioural analysis of organisms (e.g. the flocking behaviour of birds) (Klein et al. 2019; Magallanes Guijón et al. 2018).

\section{Conclusion}

The main contribution of the present paper is to provide an empirical experiment on the impact of immersion on the formation of spatial presence in virtual geo-environments. 
We began with an critical analysis of immersion and spatial presence, then focused the significance of these concepts onto the particular characteristics of geovisualization products and finally utilized them as dependent and independent variables of our test design, hypothesizing that higher levels of immersion will positively affect the map user's feeling of presence. Results obtained from a user study on a VR replica of a Caribbean coral reef confirmed this hypothesis.

Although our findings agree with research on spatial presence in fictitious and non-geographic VR environments, it should be noted that many studies published to date are rather ad hoc investigations of a still very incipient technology. Hence, the results obtained from these studies cannot be easily generalized, and the present experiment is no exception in this regard.

What is still lacking is an interdisciplinary coordinated agenda on issues of both VR and AR geo-environments, to better adjust the often fragmented current research projects. Until there is agreement regarding such a research agenda, many user studies will continue to generate more questions than answers.

Nevertheless, this study allows a first glimpse at the formation of spatial presence in immersive geo-environments, thus providing support for further research on VR geovisualization not just from a technological, but also from a user's perspective.

Acknowledgements Open access funding provided by University of Vienna.

Open Access This article is licensed under a Creative Commons Attribution 4.0 International License, which permits use, sharing, adaptation, distribution and reproduction in any medium or format, as long as you give appropriate credit to the original author(s) and the source, provide a link to the Creative Commons licence, and indicate if changes were made. The images or other third party material in this article are included in the article's Creative Commons licence, unless indicated otherwise in a credit line to the material. If material is not included in the article's Creative Commons licence and your intended use is not permitted by statutory regulation or exceeds the permitted use, you will need to obtain permission directly from the copyright holder. To view a copy of this licence, visit http://creativecommons.org/licenses/by/4.0/.

\section{References}

Ahn R, Arjmandianbagha K, Guevara Pulido M, Golth C, Rönisch M, H, S, A, T, M, T, Morten T, Elias W (2019) Scale-unexplored opportunities for immersive technologies in place-based learning. In: 2019 AGIT, University of Salzburg

Bachen C, Hernández-Ramos P, Raphael C, Waldron A (2016) How do presence, flow, and character identification affect players' empathy and interest in learning from a serious computer game? Comput Hum Behav 64:77-87

Cerdeira-Estrada S, Heege T, Kolb M, Ohlendorf S, Uribe A, Müller A, Garza R, Ressl R, Aguirre R, et al. (2012) Benthic habitat and bathymetry mapping of shallow waters in puerto morelos reefs using remote sensing with a physics based data processing. In: 2012 IEEE International Geoscience and Remote Sensing Symposium, pp 4383-4386. IEEE

Cho Y (2018) How spatial presence in VR affects memory retention and motivation on second language learning: a comparison of desktop and immersive VR-based learning. Syracuse University, Syracuse

Cummings J, Bailenson J (2016) How immersive is enough? A metaanalysis of the effect of immersive technology on user presence. Media Psychol 19(2):272-309

Edler D, Husar A, Keil J, Vetter M, Dickmann F (2018) Virtual reality (vr) and open source software: a workflow for constructing an interactive cartographic vr environment to explore urban landscapes. Kartographische Nachrichten 68(1):3-11

Edler D, Keil J, Wiedenlübbert T, Sossna M, Kühne O, Dickmann F (2019) Immersive vr experience of redeveloped post-industrial sites: the example of "Zeche Holland" in Bochum-Wattenscheid. KN J Cartogr Geogr Inf 69:267-284

Edler D, Kühne O, Jenal C, Vetter M, Dickmann F (2018) Potenziale der Raumvisualisierung in Virtual Reality (VR) für die sozialkonstruktivistische Landschaftsforschung. Kartographische Nachrichten 68(5):245-254

Hartmann T, Wirth W, Schramm H, Klimmt C, Vorderer P, Gysbers A, Böcking S, Ravaja N, Laarni J, Saari T et al (2015a) The spatial presence experience scale (spes). J Media Psychol 28:1-15

Hartmann T, Wirth W, Vorderer P, Klimmt C, Schramm H, Böcking $S$ (2015b) Spatial presence theory: state of the art and challenges ahead. In: Lombard M, Biocca F, Freeman J, IJsselsteijn W, Schaevitz RJ (eds) Immersed in media. Springer, pp 115-135

Havenith HB, Cerfontaine P, Mreyen AS (2019) How virtual reality can help visualise and assess geohazards. Int J Digit Earth 12(2):173-189

Hruby F, Ressl R, de la Borbolla Del Valle G (2019) Geovisualization with immersive virtual environments in theory and practice. Int $\mathrm{J}$ Digit Earth 12(2):123-136

Hruby F, Ressl R, del Valle GDIB, Paz OR, Sierra VA, Coutiño JHM (2019) Real geographies in virtual space: a practical workflow for geovisualization with immersive vr. In: International Congress of Telematics and Computing, Springer, pp 3-15

Iachini T, Maffei L, Masullo M, Senese V, Rapuano M, Pascale A, Sorrentino F, Ruggiero G (2018) The experience of virtual reality: are individual differences in mental imagery associated with sense of presence? Cogn Process 20:291-298

IJsselsteijn W, De Ridder H, Freeman J, Avons S (2000) Presence: concept, determinants, and measurement. In: Human vision and electronic imaging V, vol 3959, pp 520-529. International Society for Optics and Photonics

Kang S, O’Brien E, Villarreal A, Lee W, Mahood C (2019) Immersive journalism and telepresence: does virtual reality news use affect news credibility? Digit J 7(2):294-313

Kersten TP, Tschirschwitz F, Deggim S, Lindstaedt M (2018) Virtual reality for cultural heritage monuments-from $3 \mathrm{~d}$ data recording to immersive visualisation. In: Euro-Mediterranean Conference, Springer, pp 74-83

Klein K, Sommer B, Nim H, Flack A, Safi K, Nagy M, Feyer S, Zhang Y, Rehberg K, Gluschkow A et al (2019) Fly with the flock: immersive solutions for animal movement visualization and analytics. J R Soc Interface 16(153):20180794

Lee KM (2004) Presence, explicated. Commun Theory 14(1):27-50

Lombard M, Jones M (2015) Defining presence. In: Schaevitz RJ (ed) Immersed in media. Springer, New York, pp 13-34

Lütjens M, Kersten TP, Dorschel B, Tschirschwitz F (2019) Virtual reality in cartography: immersive $3 \mathrm{~d}$ visualization of the arctic clyde inlet (Canada) using digital elevation models and bathymetric data. Multimodal Technol Interact 3(1):9 
Magallanes Guijón G, Hruby F, Ressl R, Aguilar V, de la Borbolla del Valle G, Rodríguez Paz O (2018) Modelling of collective movement in immersive environments. Int Arch Photogr Remote Sens Spatial Inf Sci XLII-4:397-402

Oh C, Bailenson J, Welch G (2018) A systematic review of social presence: definition, antecedents, and implications. Front Robot AI 5:114. https://doi.org/10.3389/frobt

Regenbrecht H, Schubert T (2002) Real and illusory interactions enhance presence in virtual environments. Presence Teleoperators Virtual Environ 11(4):425-434

Schubert T (2003) The sense of presence in virtual environments: a three-component scale measuring spatial presence, involvement, and realness. Zeitschrift für Medienpsychologie 15(2):69-71

Schubert T, Crusius J (2002) Five theses on the book problem: Presence in books, film and vr. In: PRESENCE 2002-Proceedings of the fifth international workshop on Presence, Universidad Fernando Pessoa, Porto, Portugal, pp 53-59

Schubert T, Friedmann F, Regenbrecht H (2001) The experience of presence: factor analytic insights. Presence Teleoperators Virtual Environ 10(3):266-281

Schubert TW (2009) A new conception of spatial presence: once again, with feeling. Commun Theory 19(2):161-187

Seibert J, Shafer D (2018) Control mapping in virtual reality: effects on spatial presence and controller naturalness. Virtual Real 22(1):79-88

Sherman WR, Craig AB (2018) Understanding virtual reality: interface, application, and design. Morgan Kaufmann, Burlington

Skarbez R, Brooks F, Whitton M (2018) A survey of presence and related concepts. ACM Comput Surv (CSUR) 50(6):96
Slater M, Wilbur S (1997) A framework for immersive virtual environments (five): speculations on the role of presence in virtual environments. Presence Teleoperators Virtual Environ 6(6):603-616

Tamborini R, Bowman N (2010) Chaper 5 presence in video games. In: Bracken CC, Skalski P (eds) Immersed in media. Routledge, New York, pp 105-128

Tschirschwitz F, Richerzhagen C, Przybilla HJ, Kersten TP (2019) Duisburg 1566: transferring a historic $3 \mathrm{~d}$ city model from google earth into a virtual reality application. PFG-J Photogr Remote Sens Geoinf Sci 87(1-2):47-56

Vasconcelos-Raposo J, Bessa M, Melo M, Barbosa L, Rodrigues R, Teixeira C, Cabral L, Sousa A (2016) Adaptation and validation of the igroup presence questionnaire (ipq) in a portuguese sample. Presence Teleoperators Virtual Environ 25(3):191-203

Wirth W, Hartmann T, Böcking S, Vorderer P, Klimmt C, Schramm H, Saari T, Laarni J, Ravaja N, Gouveia F et al (2007) A process model of the formation of spatial presence experiences. Media Psychol 9(3):493-525

Wirth W, Hofer M, Schramm H (2012) The role of emotional involvement and trait absorption in the formation of spatial presence. Media Psychol 15(1):19-43

Yang Y, Jenny B, Dwyer T, Marriott K, Chen H, Cordeil M (2018) Maps and globes in virtual reality. In: Computer graphics forum, Wiley Online Library, vol 37, pp 427-438. https://onlinelibrary. wiley.com/doi/abs/10.1111/cgf.13431

Zambrano A, Padilla O, Toulkeridis T, Zapata J, Ordoñez E, Mato F (2017) Software constraints for caves' virtual environments modeling. In: 2017 IEEE Symposium Series on Computational Intelligence (SSCI), pp 1-5. IEEE 